\title{
Mid-ocean ridge jumps associated with hotspot magmatism
}

\section{Eric Mittelstaedt $^{\mathrm{a}^{*}}$, Garrett Ito ${ }^{\mathrm{a}}$ and Mark D. Behn ${ }^{\mathrm{b}}$}

a. School of Ocean and Earth Science and Technology, University of Hawaii, 1680 East West Rd., Honolulu, HI USA

b. Woods Hole Oceanographic Institute, Woods Hole, Massachusetts USA

* corresponding author - email: mittelst@hawaii.edu, telephone: (808) 956-4432, fax: (808) 956-5154

\section{ABSTRACT}

Hotspot-ridge interaction produces a wide range of phenomena including excess crustal thickness, geochemical anomalies, off-axis volcanic ridges and ridge relocations or jumps. Ridges are recorded to have jumped toward many hotspots including, Iceland, Discovery, Galápagos, Kerguelen and Tristan de Cuhna. The causes of ridge jumps likely involve a number of interacting processes related to hotspots. One such process is reheating of the lithosphere as magma penetrates it to feed near-axis volcanism. We study this effect by using the hybrid, finite-element code, FLAC, to simulate twodimensional (2-D, cross-section) viscous mantle flow, elasto-plastic deformation of the lithosphere and heat transport in a ridge setting near an off-axis hotspot. Heating due to magma transport through the lithosphere is implemented within a hotspot region of fixed width. To determine the conditions necessary to initiate a ridge jump, we vary four parameters: hotspot magmatic heating rate, spreading rate, seafloor age at the location of the hotspot and ridge migration rate. Our results indicate that the hotspot magmatic heating rate required to initiate a ridge jump increases non-linearly with increasing spreading rate and seafloor age. Models predict that magmatic heating, itself, is most likely to cause jumps at slow spreading rates such as at the Mid-Atlantic Ridge on Iceland. In contrast, despite the higher magma flux at the Galápagos hotspot, magmatic heating alone is probably insufficient to induce a ridge jump at the present-day due to the 
intermediate ridge spreading rate of the Galápagos Spreading Center. The time required to achieve a ridge jump, for fixed or migrating ridges, is found to be on the order of $10^{5}$ $10^{6}$ years. Simulations that incorporate ridge migration predict that after a ridge jump occurs the hotspot and ridge migrate together for time periods that increase with magma flux. Model results also suggest a mechanism for ridge reorganizations not related to hotspots such as ridge jumps in back-arc settings and ridge segment propagation along the Mid-Atlantic Ridge.

Keywords: ridge-hotspot interaction; ridge jump; magmatism; back-arc spreading; numerical modeling

\section{INTRODUCTION}

The evolution and geometry of mid-ocean ridges influences the thickness [1], shape and movement [2-4] of the tectonic plates. Repeated changes in the location of ridge axes, such as those caused by hotspot influenced asymmetric spreading [5], ridge segment propagations [6] or discrete ridge jumps, can significantly alter the global pattern of plate tectonics through time.

Many places along the mid-ocean ridge network have experienced ridge jump behavior including localities near Ascension, Conrad Rise, Discovery, Galápagos, Iceland, Ninety-East Ridge, Louisville, Shatsky Rise, Shona and Tristan de Cuhna [7-16]. Although the above jumps all cause a discrete change in the location of the ridge, the distance over which a jump occurs and the type of ridge boundary varies. Shatsky Rise, which is associated with large outputs of magma, is the location of a series of triple junction jumps that repeatedly displaced the triple junction by up to $800 \mathrm{~km}$ [7]. In 
contrast, relocations of ridge axes over much smaller distances $(10-100 \mathrm{~km})$ occurred near Ascension, Galápagos and Iceland (Figure 1). Intermediate between the very large jumps at Shatsky Rise and the smaller jumps at Ascension, Galápagos and Iceland, were a series of at least 4 ridge jumps near the Ninety-East Ridge, transferring portions of the Antarctic plate to the Indian plate. At each of the above locations, hotspot-ridge interaction is likely to be the dominant cause of ridge jump initiation.

Assuming hotspots overlie sources of anomalously hot asthenosphere, there are several mechanisms that can promote ridge jumps including lithospheric tension induced by buoyant and convecting asthenosphere [17], mechanical and thermal thinning of the lithosphere due to hot flowing asthenosphere [18], and penetration of magma through the plate [19]. This study focuses on the last process by quantifying the effects of lithospheric heating caused by hotspot magmatism. We examine how seafloor age at the hotspot, spreading rate, magmatic heating rate (magma flux) and ridge migration influence the timescale and viability of ridge-jumps. Results indicate that magmatic heating, alone, can cause ridge jumps for geologically reasonable magma fluxes only in young, slow-moving lithosphere. Further we show that magmatic heating can also promote jumps in back-arc spreading systems such as the Marianas as well as propagation of ridge segments at slow-spreading ridges such as the Mid-Atlantic Ridge.

\section{CONCEPTUAL AND MATHEMATICAL MODEL}

\subsection{Conceptual Model}


Figure 2 illustrates our conceptual model for a ridge jump induced by magmatic heating from an off-axis hotspot. Magma is produced by the hotspot beneath the plate and then penetrates the lithospheric thermal boundary layer to create hotspot volcanoes. During volcanism, some of the heat carried by the magma is transferred to the lithosphere, weakening it over time. Heating of the lithosphere is controlled by the balance between the heat flux from the magma, advection due to plate spreading and surface heat flow. If the magmatic heating rate is sufficient, the lithosphere will thin until new rifting begins over the hotspot. The weaker, new rift then becomes an established ridge axis and spreading at the former axis ceases.

\subsection{Mathematical and Numerical Model}

Using the FLAC (Fast Lagrangian Analysis of Continua) method [20,21], we solve the equations describing conservation of mass and momentum for a visco-elasticplastic continuum in 2-D Cartesian geometry [22]. The model domain is $150 \mathrm{~km}$ laterally by $50 \mathrm{~km}$ vertically and is made up of a grid of 300 by 100 Lagrangian (i.e. the grid deforms with the model) quadrilaterals each composed of two pairs of triangular elements. Since deformation of the grid degrades numerical accuracy, model quantities are linearly interpolated to a new grid when the minimum angle of any triangle is less than a given value $\left(10^{\circ}\right)$. The ductile asthenosphere is approximated as a visco-elastic material with a non-Newtonian, temperature-dependent viscosity, and the strong, brittle portion of the lithosphere is treated as an elastic-perfectly-plastic material subject to a Mohr-Coulomb failure criteria. Faulting in the model develops through localization of strain by a reduction in cohesion from $44 \mathrm{MPa}$ to $4 \mathrm{MPa}$ over a plastic strain of 0.25 (i.e. 
over $\sim 500 \mathrm{~m}$ of fault offset). Rheologically, the model consists of a $6-\mathrm{km}$-thick crust of dry diabase [23] and a dunite mantle [24]. The mechanical boundary conditions include a horizontal, uniform velocity equal to the half spreading rate, $U$, on the two vertical sides of the box, a stress free top surface, and zero shear and hydrostatic pressure on the base.

Temperature, $T$, is calculated using the following advection-diffusion equation,

$$
\frac{\partial T}{\partial t}=\kappa \nabla^{2} T-\overline{\mathbf{u}} \cdot \nabla T+\frac{(\text { source })}{\rho c_{p}},
$$

where $\kappa$ is the thermal diffusivity $\left(3 \times 10^{-6} \mathrm{~m}^{2} \mathrm{~s}^{-1}\right), t$ is time, $\overline{\boldsymbol{u}}$ is the velocity vector, $\rho$ is the density (2900 $\mathrm{kg} \mathrm{m}^{-3}$ for the crust and $3300 \mathrm{~kg} \mathrm{~m}^{-3}$ for the mantle) and $c_{p}$ is the specific heat $\left(1000 \mathrm{~J} \mathrm{C}^{-1} \mathrm{~kg}^{-1}\right)$ [25]. See Table 1 for definitions of all variables. The thermal boundary conditions consist of an isothermal top, set to $0^{\circ} \mathrm{C}$, and a bottom boundary equal to the temperature of a half-space cooling model at $50 \mathrm{~km}$ depth with thermally reflecting side boundaries. The initial temperature field is described by an analytical solution for half-space cooling [e.g. 1] with an asthenospheric temperature of $1300^{\circ} \mathrm{C}$ (appropriate for shallow upper mantle that has had latent heat of melting removed from it [e.g. 26]). Numerically, heat advects with the grid and thermal diffusion is calculated using explicit finite differences.

Magmatic heating is incorporated at the ridge as well as at the off-axis hotspot. This is done in the "source" term of Eq. (1), which is defined as $q_{\text {ridge }}$ in a specified zone at the ridge axis and $q_{\text {hotspot }}$ within an off-axis hotspot zone, both of fixed width, $w$. Outside of the ridge axis and hotspot zones, $q_{r i d g e}$ and $q_{\text {hotspot }}$ are equal to 0 . Within the hotspot zone, $q_{\text {hotspot }}$ is defined by,

$$
q_{\text {hotspot }}=\rho c_{p} \beta F(x)\left(T_{\text {asth }}-T(x, z, t)\right),
$$


where $T_{a s t h}$ is the temperature of both the asthenosphere and the penetrating magma $\left(1300^{\circ} \mathrm{C}\right), \beta$ is the magnitude of the hotspot heating rate and $x$ and $z$ are the horizontal and vertical coordinates. The constant, $\beta$, controls the magnitude of $q_{\text {hotspot }}$ and is set manually. The function $F(x)$ is a Gaussian function that describes the dependence of $q_{\text {hotspot }}$ on horizontal position, $x$,

$$
F(x)=\frac{w}{\sigma \sqrt{2 \pi}} \exp \left(\frac{-\Delta x^{2}}{2 \sigma^{2}}\right) \cdot H[w-\Delta x],
$$

where $\sigma$ is the standard deviation of the Gaussian distribution $\left(\sigma=w \cdot(2 \sqrt{2 \ln (2)})^{-1}\right), \Delta x$ is the difference between $x$ and the center of the hotspot and $H$ is the Heaviside function which is equal to 0 outside of the hotspot heating zone and 1 within this zone. For most cases, we assume a reference width of the hotspot heating zone of $w=2 \mathrm{~km}$, which is similar to the width of the region of long period earthquakes (often associated with magma movement) between 12-24 km depth beneath Kilauea [27]. We discuss the effects of varying $w$ in Section 3.3.

We also consider magmatic heating due to the accretion of magma to form the oceanic crust. The accretion zone, $w$, is set to be $2 \mathrm{~km}$ wide and $6 \mathrm{~km}$ in height with $q_{\text {ridge }}$ defined by,

$$
q_{\text {ridge }}=\rho c_{p} \cdot F(x) \frac{\left(T_{a s t h}-T(x, z, t)\right) \cdot R(t)}{w} .
$$

where $R(t)$ is the ridge divergence rate $(R=2 U$ at $t=0)$ and $F(x)$ is defined by Equation (3) except that here $\Delta x$ is the difference between $x$ and the location of the ridge axis. Below, we examine model solutions both with and without $q_{\text {ridge }}$.

Because little is known about the mechanisms of magma transport through the lithosphere, the above equations for magmatic heating are designed to be as general as 
possible and to not require defining a specific transport mechanism. Eq (2), for example, is the solution for heating of material between two vertical channels of magma of constant temperature. The form of the equation should be reasonable for a wide range of channel geometries and spacing, with the requirement that magma temperature remains close to its starting value $\left(T_{a s t h}\right)$, a condition that would hold so long as liquid magma survives to the surface without completely freezing. For reference, the above conditions, as well as the range of heat fluxes simulated by our models, would be met with a scenario involving vertical magma channels having flow rates described by Poiseuille flow, widths starting at $0.2-1.25 \mathrm{~m}$ but decreasing due to partial freezing, each lasting for $0.25-1.5$ days, and re-forming in the hotspot magma zone every $40-150$ years.

The geologic implications for the dependence on the temperature contrast between the magma and host rock are that the majority of heat transfer occurs in the cool thermal boundary layer, regardless of its thickness. At both normal and hotspot affected mid-ocean ridges, most of the magmatic heat transfer occurs near to or within the crust $[28,29]$. Away from the ridge axis, our model predicts a thicker thermal boundary layer and thus a larger depth range of magmatic heating. Currently, the depth range of off-axis crystallization and the related thermal structure are poorly known.

Finally, while hydrothermal circulation is thought to be important at shallow depths [30], we do not explicitly include this effect. The scaling laws that we establish (Section 3.3), however, depend on the difference in the integrated heating rates between the off- and on-axis heating zones. Thus our overall results are robust to the extent that hydrothermal circulation is not extremely different between the ridge and hotspot. If hydrothermal cooling contributes a larger fraction of the heat budget of the thin thermal 
boundary layer at mid-ocean ridges, our predictions will tend to under-estimate the importance of off-axis magmatic heating in promoting ridge jumps.

\subsection{Geologic parameters}

We consider three types of simulations. Type 1 involves magmatic heating at an off-axis hotspot located a fixed distance from the ridge, but does not include ridge-axis heating $\left(q_{\text {ridge }}=0\right)$. Type 2 includes magmatic heating at a fixed hotspot and at the ridge axis. For Type 1 and 2 cases, the hotspot magma penetration zone is located beneath seafloor of ages 1 or $2 \mathrm{Myr}$, with half spreading rates of $U=10,20$, or $30 \mathrm{~km} / \mathrm{Myr}$ and a variety of input heating rates, $q_{\text {hotspot }}\left(\beta\right.$ ranges between $1.8 \times 10^{-10} \mathrm{~s}^{-1}$ and $\left.26.7 \times 10^{-10} \mathrm{~s}^{-1}\right)$. This range of parameters is not meant to span the geologic range, but rather to yield an appreciable range of the fundamental parameters that control the system.

Finally Type 3 cases have a hotspot magma zone that migrates relative to the ridge axis (or the ridge migrates relative to a "fixed" hotspot) without ridge axis heating. These cases have a spreading rate of $20 \mathrm{~km} / \mathrm{Myr}$ with three heating rates $\left(\beta=1.8 \times 10^{-10} \mathrm{~s}^{-}\right.$ ${ }^{1}, 4.4 \times 10^{-10} \mathrm{~s}^{-1}, 8.9 \times 10^{-10} \mathrm{~s}^{-1}$ ) and ridge-hotspot migration rates of $U_{m i g}=10-30 \mathrm{~km} / \mathrm{Myr}$.

Models are run until the temperature has reached steady state without a ridge jump (for Types 1,2), a ridge jump occurs (for Types 1,2) or the magma penetration zone migrates across the model domain (for Type 3). Ridge jumps are defined as complete when the divergence rate at the off-axis intrusion zone is equal to $80 \%$ of the full spreading rate of the original ridge axis (Figure 3c). In the following section we first quantify the hotspot magmatic heating fluxes needed to generate ridge jumps and then apply our results to hotspot-ridge environments where magma fluxes have been estimated 
as well as to the Mariana back-arc and non-hotspot influenced areas of the Mid-Atlantic Ridge.

\section{RESULTS}

\subsection{Time Evolution: Fixed Hotspot Magma Penetration Zone (Type 1 and 2)}

For Types 1 and 2, the ridge system is first allowed to equilibrate to steady state without a hotspot $\left(q_{\text {hotspot }}=0\right)$. Then, at time $t=0$ a hotspot is initiated and $q_{\text {hotspot }}$ is imposed as in Eq. 2. Immediately after $t=0$, spreading is fully accommodated at the ridge axis and hotspot magmatism begins to thin and warm the off-axis lithosphere (Figure 3, 4). Continued hotspot heating leads to weakening of the off-axis lithosphere, which initiates rifting and perturbs the mantle flow pattern, such that small amounts of upwelling begin to occur near the hotspot zone. As the off-axis lithosphere continues to weaken, larger divergence rates develop and induce asthenospheric upwelling (Figure 4). In models that generate a ridge jump, after a period of magmatism (0.05-3.0 Myr) a relatively short period ( $\sim 0.2-0.8 \mathrm{Myr})$ of coeval rifting occurs during the shift of spreading from the old axis to the new rift. During this period, the divergence rates at the two rifts change rapidly, but the lithosphere between them experiences small lateral velocity gradients, acting as a "microplate". Throughout this "microplate" stage, the divergence rate decreases sharply at the original spreading axis. This causes cooling and strengthening of the lithosphere at the original axis and faster spreading at the new rift. Finally, as the divergence at the original ridge axis ceases, the off-axis location establishes stable seafloor spreading. 


\subsection{Controlling Parameters}

To understand the mechanisms that control the initiation of ridge jumps, we introduce scaling relations involving three basic parameters: the rate of magmatic heating at the hotspot, the rate of magmatic heating at the ridge axis, and the heating rate required to thin the lithosphere. The total magmatic heating rate at the hotspot at the onset of hotspot magmatism $(t=0)$ is,

$$
Q_{\text {hotspot }}=\int_{0}^{\infty} \int_{-w / 2}^{w / 2}\left(q_{\text {hotspot }}\right)_{t=0} d x d z
$$

The total heating rate at the ridge axis, also at $t=0$, is,

$$
Q_{\text {ridge }}=\int_{0}^{\text {zcrust }} \int_{-w / 2}^{w / 2}\left(q_{\text {ridge }}\right)_{t=0} d x d z,
$$

where $z_{\text {crust }}$ is the depth of the crust $(6 \mathrm{~km})$. We re-emphasize that because the actual heating rates (Eqs. 3, 4) are time-dependent, the above parameters are defined based on the temperature structure at $t=0$.

The third heating parameter, $Q_{\text {thin }}$, is a measure of the heating rate required to thermally dissolve the off-axis lithosphere so that it is as weak as the ridge-axis lithosphere. We define $D$ to be the lateral distance over which the lithosphere is thinned by the hotspot (Figure 5). To quantify the required heating rate, we examine the balance of heat advected into and out of this zone. The heat being advected into the hotspot magma zone (Figure 5) is measured by the influx of the unperturbed thermal boundary layer $(T(z)$ at the hotspot center when $t=0)$

$$
Q_{i n}=\rho c_{p} U \int_{0}^{z \max } T(z)_{t=0} d z
$$


where $z_{\max }$ is the maximum thickness of the lithospheric thermal boundary layer as defined arbitrarily by the $1170^{\circ} \mathrm{C}$ isotherm at the center of the hotspot. The outgoing heat flux (again at the hotspot center) transported by the "dissolved" lithosphere will be,

$$
Q_{\text {out }} \sim \rho c_{p} U \int_{0}^{z \max } T_{\text {asth }} d z
$$

Should a ridge jump occur, the net heat advected out of the box of width $D$ is thus

$$
Q_{\text {thin }}=Q_{\text {out }}-Q_{\text {in }}=\rho c_{p} U\left[\int_{0}^{z \max }\left(T_{\text {asth }}-T(z)\right)_{t=0} d z\right] .
$$

In the absence of conduction out of the seafloor and asthenospheric flow into the base of the box, $Q_{\text {thin }}$ would therefore be the total heating rate in the box required to dissolve the lithosphere in the time it crosses the heating zone. Note that $Q_{\text {thin }}$ incorporates information about both the spreading rate and the age of the seafloor at the hotspot (through the thickness, $z_{\max }$, in the integration limits).

The time scale for ridge jump initiation is related to the total width $D$ that the lithospheric thickness is perturbed. Magmatic heating at the hotspot occurs in a zone of fixed width (w), but heat diffusion causes lithospheric thinning over the larger distance, $D$ (Figure 5). The approximate balance between advection of relatively cool (i.e., normal) lithospheric material toward the hotspot due to spreading $\left(Q_{i n}\right)$ and diffusion of excess heat away from the hotspot determines the ridge-ward boundary of $D$. Equating the timescale needed to advect heat a distance $D-w / 2$ and the characteristic diffusion timescale, $(D-w / 2)^{2} / \kappa$, the total width of lithospheric thinning is approximately $D \sim w / 2+$ $\kappa / U$. Results will show that an appropriate time scale for the process of magmatic heating and eventual ridge jump is the time it takes a piece of lithosphere to cross the zone of lithospheric thinning, 


$$
t_{\text {cross }}=D / U \equiv(w / 2+\kappa / U) / U .
$$

\subsection{Scaling: Fixed Hotspot Magma Penetration Zone (Type 1 and 2)}

Ridge jumps in Type 1 (no ridge heating) cases are promoted by greater magmatic heating (measured by $Q_{\text {hotspot}}$ ) and are inhibited by thicker (older) or faster moving lithosphere (measured by $Q_{\text {thin }}$ ). Indeed, we find that, for a given value of $Q_{\text {thin }}$, there is a minimum value of $Q_{\text {hotspot }}$ required to initiate a ridge jump and that this minimum value increases with $Q_{\text {thin }}$ (Figure 6A). Similar behavior is seen with cases of Type 2, but the on-axis heating requires that the minimum value of $Q_{\text {hotspot }}$ for a ridge jump be greater. Examining Type 1 and 2 cases together (Figure 6A), we find that the key parameter determining ridge jump formation is how much $Q_{\text {hotspot }}$ exceeds the on-axis magmatic heating rate (i.e., $Q_{\text {hotspot }} Q_{\text {ridge }}$ ). Specifically, a ridge jump will occur for sufficient values of $Q_{\text {hotspot }} Q_{\text {ridge }}$ to weaken the plate such that the lithosphere off-axis becomes as weak as or weaker than the lithosphere at the original ridge-axis. Model results indicate that this occurs approximately when (Figure 6A)

$$
\left(Q_{\text {hotspot }}-Q_{\text {ridge }}\right) \geq M Q_{\text {thin }}{ }^{a},
$$

or when the ratio,

$$
Q_{\text {ratio }}=\left(Q_{\text {hotspot }} Q_{\text {ridge }}\right) / M Q_{\text {thin }}{ }^{a} \geq 1,
$$

where $M\left(=3.4 \times 10^{-3}\right)$ and $a(=2.68)$ are empirically fit constants.

The time from the initiation of the hotspot to the formation of a ridge jump $\left(t_{j u m p}\right)$ is shown in Figure 6B. For values of $Q_{\text {ratio }}$ near 1, the value of $t_{\text {jump }}$ is large; as $Q_{\text {ratio }}$ increases, $t_{j u m p}$ decreases asymptotically toward zero. These results illustrate a wide range of different, sometimes competing, effects. For example, for a given excess 
heating rate $Q_{\text {hotspot }}-Q_{\text {ridge, }} t_{\text {jump }}$ increases with increasing spreading rate (and $Q_{\text {thin }}$ ) until the heating rate is insufficient to weaken the lithosphere faster than the material can be advected through the magma penetration zone. Alternatively, for a given spreading rate (and $Q_{\text {thin }}$ ), increases in $Q_{\text {hotspot }} Q_{\text {ridge }}$ will decrease the time required to achieve a ridge jump as material within the hotspot heating zone is heated more rapidly. Scaling $t_{\text {jump }}$ by the time required to cross the zone of lithospheric thinning, $t_{\text {cross }}$, allows the relationship to be described by a single, empirical scaling law (Figure 6c),

$$
\frac{t_{\text {jump }}}{t_{\text {cross }}}=7.82 \cdot Q_{\text {ratio }}^{-2}+1.25 \cdot Q_{\text {ratio }}^{-1}+0.117 .
$$

Lastly, the width $w$ of the off-axis heating zone also affects the time and the minimum integrated heating rate, $Q_{\text {hotspot }}$, required to initiate a ridge jump (Figure 7). For a fixed $Q_{\text {hotspot }}=151 \mathrm{~kJ} \mathrm{~m}^{-1} \mathrm{~s}^{-1}$, a half spreading rate of $20 \mathrm{~km} / \mathrm{Myr}$, and a plate age of 2 Myr we varied $w$ between 1 and $40 \mathrm{~km}$. Models predict that as $w$ increases from $1 \mathrm{~km}$ to $12 \mathrm{~km}, t_{\text {jump }}$ decreases from $0.575 \mathrm{Myr}$ to $0.325 \mathrm{Myr}$. For $w$ increasing from $\sim 15 \mathrm{~km}$ to $40 \mathrm{~km}$, the trend reverses such that $t_{\text {jump }}$ increases to $0.75 \mathrm{Myr}$. This non-monotonic relationship is complex and is likely caused by the interaction of several factors. For example, on one hand, a wider heating zone implies a large value of $t_{\text {cross }}$, which according to (12) would tend to increase $t_{\text {jump }}$. But on the other hand, a wider heating zone results in a smaller average value of $Q_{\text {thin }}$ which is a consequence of higher average initial temperatures across the heating zone due to the more rapid shoaling of isotherms on the ridgeward side of the heating zone compared to the opposite side. The lower average $Q_{\text {thin }}$ causes a larger average $Q_{\text {ratio }}$, and by (12), tends to increase $t_{\text {jump }}$. Thus, in the above test cases, increasing $w$ up to widths comparable to those of the neovolcanic 
zone on Iceland results in values of $t_{\text {jump }}$ within about $25 \%$ of that obtained by our reference width of $2 \mathrm{~km}$.

\subsection{Time Evolution: Migrating Magma Intrusion Zone (Type 3)}

For Type 3 cases we initiate a hotspot at a distance $40 \mathrm{~km}$ to the right of the ridge axis at $t=0$. The hotspot migrates to the left (or the ridge migrates to the right in the hotspot reference frame) at a specified rate, $U_{\text {mig. }}$ As the hotspot migrates toward the ridge axis, the lithosphere thins asymmetrically over a broad area (Figure 4). Eventually, if the hotspot heating rate is sufficient, rifting begins at the hotspot. Similar to Type 1 and 2 cases, incipient rifting causes hot mantle to rise and further weaken the new rift which is followed by further rifting, and soon thereafter a ridge jump. The new ridge axis then migrates along with the hotspot. For cases in which the hotspot migration rate, $U_{\text {mig, }}$ equals or exceeds $U$, models predict the hotspot and ridge to eventually separate. The hotspot then proceeds to move away from the ridge axis. For cases in which the hotspot heating rate is too small, the ridge never jumps and the hotspot migrates across the model with little effect on the lithosphere.

\subsection{Scaling: Migrating Magma Intrusion Zone (Type 3)}

Figure 8a displays $Q_{\text {ratio }}$, calculated from Eqs. 5-7 and the initial temperature structure at time $t=0$ as a function of the distance from the ridge. In this plot, $Q_{\text {ratio }}$ is computed based on the $Q_{\text {thin }}$ and $Q_{\text {hotspot }}$ values that are present at $t=0$ just before the initiation of magmatic heating, not the time-dependent temperatures throughout the simulation. Different curves are for different values of $\beta$ (heating rate magnitude, Eq. 2), 
but for the same spreading rate $(20 \mathrm{~km} / \mathrm{Myr})$. For each value of $\beta$, we explore three different hotspot migration rates (relative to the ridge axis), $U_{\text {mig }}=10,20$ and $30 \mathrm{~km} / \mathrm{Myr}$.

When the hotspot migrates toward the ridge, the axis jumps to the hotspot at a location (grey circles Fig. 8a) that depends upon $Q_{\text {ratio }}$ and the migration rate of the hotspot. Faster migration rates initiate ridge jumps closer to the ridge axis than do slower migration rates (i.e. a faster migration rate moves the hotspot closer to the ridge in the time required to sufficiently thin the lithosphere). Like the non-migrating cases (Type 1, 2 ), jumps only occur when the $Q_{\text {ratio }}$ is near to or greater than 1 . The lowest value of $\beta$ only achieves a $Q_{\text {ratio }} \geq 1$ very close to the ridge axis and therefore a ridge jump does not occur before the hotspot migrates to the original ridge location in our numerical simulations.

After a ridge jump has occurred, the ridge and hotspot are predicted to migrate together for a distance that also depends on $Q_{\text {ratio }}$ and $U_{\text {mig }}$ (Figure $8 \mathrm{~b}$ ). Here $Q_{\text {ratio }}$ is the same function of $Q_{\text {hotspot }}$ and $Q_{\text {thin }}$ based on the $t=0$ temperature profiles, but is plotted as a function of distance from the new ridge axis right after it jumped. The location of separation occurs closer to the ridge axis with increasing $U_{\text {mig. }}$. For cases in which the $Q_{\text {ratio }}$ remains $>1$ or $U_{m i g}<U$, the ridge remains captured and continues to migrate with the hotspot over the distance spanned by the numerical box.

\section{DISCUSSION: Importance of hotspot magmatic heating to natural systems}

\subsection{To Jump or Not to Jump: Iceland versus the Galápagos}


There are many near-ridge hotspots around the globe, but only some display recent ridge jumps. We focus on two example systems for which the tectonic evolution is well understood and for which hotspot magma fluxes can be estimated: Iceland-MAR where ridge jumps have recently occurred and Galápagos where ridge relocations have recently ceased.

The Galápagos spreading center (GSC) has moved north relative to the hotspot for tens of Myr [14,31]. Between 5-10 Ma, the GSC and Galápagos were located very close to each other and the ridge experienced several distinct jumps. Between $\sim 2.5-5 \mathrm{Ma}$, the GSC was "captured" by the hotspot and remained close to it, but did not display discrete jump activity at the resolution of the available geophysical data. Since $\sim 2.5 \mathrm{Ma}$, the GSC has remained separate from the Galápagos hotspot and has not appeared to have jumped. At the present day, the segments west and east of the $90.5^{\circ} \mathrm{W}$ transform fault are 260 and $200 \mathrm{~km}$ north of the hotspot, respectively.

Iceland was the site of at least four major jumps of the Mid-Atlantic Ridge (MAR) in the last $\sim 16$ million years ([32], Figure 1). Migration of most of the MAR to the northwest at approximately $5-17 \mathrm{~km} / \mathrm{Myr}[33,34]$ with respect to the hotspot was punctuated by jumps of individual ridge segments on Iceland toward the hotspot. Recent dating of dikes along a $350 \mathrm{~km}$ transect across northern Iceland indicates that the most recent jump (initiated at $\sim 7.8 \mathrm{Ma}$ ) occurred into $\sim 1$ Myr-old lithosphere from the Skagafjordur rift to the Northern Volcanic Zone (NVZ) [35]. Geological estimates, however, place the former ridge axis tens of kilometers to the west on the Skagi peninsula suggesting a jump into 4 Myr old seafloor [8]. We thus bracket the seafloor age to which jumps occur between 1-4 Myrs. After initiation of the ridge jump, coeval rifting of the 
NVZ and the former ridge axis ensued for approximately 3.5 Myr with the old rift dying at $\sim 3 \mathrm{Ma}[8]$.

Using the relationship between $Q_{\text {hotspot }} Q_{\text {ridge }}$ and $Q_{\text {thin }}$ (Figure 6A), we can now assess whether thermal weakening alone is likely to have initiated the ridge jumps at the Iceland and Galápagos hotspots. $Q_{\text {thin }}$ can be estimated for a given location based upon the age of the overlying lithosphere and a basic square-root-of-age cooling profile. To calculate $Q_{\text {hotspot }}$, the heat transferred to the lithosphere is assumed to be equal to the magma flux times the latent heat of fusion of the magma for latent heat values between 400 and $600 \mathrm{~kJ} / \mathrm{kg}$. This assumption will tend to maximize the effects of magmatic heating at both the ridge and hotspot, so the effect of this assumption on $Q_{\text {hotspot }}-Q_{\text {ridge }}$ is not clear at this point. The magma flux used is based upon crustal thicknesses derived from geophysical data. $Q_{\text {ridge }}$ is calculated in a similar manner as $Q_{\text {hotspot }}$, but with a magma flux based on the spreading rate of the given ridge and a crustal output at that ridge.

For Iceland, $Q_{\text {thin }}$ is calculated for 1-4 Myr old lithosphere (Eq. 7). $Q_{\text {ridge, }}$ is calculated assuming a 20-km-thick crust (crustal thickness estimate for western Iceland [36]) multiplied by a spreading rate of $20 \mathrm{~km} / \mathrm{Myr}$. $Q_{\text {hotspot }}$ is estimated based on 10$25 \mathrm{~km}$ of additional crust ( $45 \mathrm{~km}$ directly above the hotspot or $30 \mathrm{~km}$ in the NVZ minus $20 \mathrm{~km}$ in western Iceland) assumed to be associated with the hotspot and a full spreading rate of $20 \mathrm{~km} / \mathrm{Myr}$.

For the Galápagos, $Q_{\text {ridge }}$ is estimated from the maximum crustal thickness of $9 \mathrm{~km}$ at the ridge axis just north of the hotspot [37] and a full spreading rate of $60 \mathrm{~km} / \mathrm{Myr}$. We estimate $Q_{\text {hotspot }}$ based on the average magmatic flux estimated for the islands of $1.3 \times 10^{5}$ 
$\mathrm{km}^{3} / \mathrm{Myr}$ (per km parallel to the ridge) [38]. $Q_{\text {thin }}$ is calculated based on 8 to $8.5 \mathrm{Myr}$-old lithosphere at the current presumed location of the hotspot (Fernandina Island).

Figure 9 shows the estimated values of $Q_{\text {hotspot }} Q_{\text {ridge }}$ for Iceland and the Galápagos versus our estimates of $Q_{\text {thin }}$ at these hotspots. Figure 10 illustrates the model estimates of the required excess heat and magma fluxes for the appropriate spreading rates and seafloor ages. Comparisons to our model results suggest that lithospheric heating due to magma penetration alone is insufficient to cause the Galápagos Spreading Center to jump to the current hotspot location. Taking the estimated $Q_{\text {hotspot }}-Q_{\text {ridge }}$ for the Galápagos and assuming constant spreading rate through time, the maximum age of lithosphere for which the Galápagos can initiate a ridge jump is $\sim 1$ Ma. These results are consistent with the lack of a Galápagos ridge jump over the past few million years as the ridge migrated away from the hotspot [31].

Our estimates for Iceland, however, show a different picture. In this case, for jumps to seafloor up to $1.5 \mathrm{Myr}$ old, the upper range of magma flux of the Iceland hotspot (in excess of the hotspot-influenced ridge axis) exceeds that predicted by our scaling law to cause a ridge jump. While the study of dike ages suggests that the Icelandic ridge jumps occurred to crust as young as 1 Myr old, the relation of the dated dikes to the former ridge axis is unclear due to a lack of trace-element data. It is thus likely that the ridge jumped to older crust. A jump to crust of $4 \mathrm{Myr}$, based on the geologic evidence [8], would likely require other mechanisms in addition to magmatic heating to initiate rifting. Although seafloor age is a significant factor, the most important difference between the Galápagos and Iceland localities is the spreading rate. Despite the lower igneous magma flux associated with the Icelandic hotspot, the slow 
moving lithosphere allows greater time to heat a given piece of lithosphere (Figure 10).

This is the main reason that magmatic heating is predicted to be more important at Iceland than at Galápagos.

Another model prediction to compare with observations is the duration of coeval rifting while the ridge jump is in progress. Models predict a duration of coeval rifting of 0.2-0.8 Myr that is an order of magnitude shorter than the $3.5 \mathrm{Myr}$ duration estimated during the last ridge jump on Iceland [8]. This discrepancy further suggests either that magmatic heating changed in time differently than simulated in our models, or that different processes are also important to the evolution of Icelandic ridge jumps.

\subsection{Hotspot-Ridge Migration}

Results from Type 3 (migrating hotspot) cases show that during the time in which the ridge is "captured" by the hotspot, the hotspot and ridge-axis migrate together, but do not exhibit discrete jumps. After the separation of the ridge and hotspot, no further ridge jump behavior occurs due to the low value of the $Q_{\text {ratio }}$. On Earth there is evidence for ridge "capture" via steady ridge migration as well as discrete ridge jumps. The large distances involved in jumps at the Ninety-East Ridge and Shatsky Rise evident in magnetic anomalies $[7,11,16]$, as well as the age dating of dikes on Iceland [35] suggest that ridge jumps at these locations are discrete events. Alternatively, after the last jump of the Galápagos Spreading Center ( $\sim 5 \mathrm{Ma})$, asymmetric spreading kept the ridge close to the hotspot for $\sim 2.5$ Myr probably without discrete jumps [31].

The failure of our models to predict discrete jumps as the ridge moves away from the hotspot center, suggests that processes other than those considered here are at work. 
For example, upwelling, warm mantle plumes thermally and mechanically thin the lithosphere and can influence melt migration through changes to the slope of the lithosphere [39-42]. The amount of lithospheric thinning depends on the ratio of the thinning rate to the hotspot migration rate [18]. In the case of a migrating, ridge-centered plume, the thin lithosphere at the ridge axis could focus melt to the ridge [41] while the plume moves off-axis. This could keep melt focused to the ridge axis until the plume migrates a sufficient distance such that plume-generated magma cannot make it back to the ridge. This behavior would result in a gap in hotspot volcanism after a ridge jump, which could be tested with further field observations. A similar change in the pattern of volcanism due to the slope of the lithosphere is proposed by Sleep [43] for plumes approaching ridges. Another process that may influence the formation of repeated ridge jumps is variations in magma flux. Iceland, for example, may experience pulses of magmatism indicated by anomalous V-shaped ridges along the Mid-Atlantic Ridge [4446]. Variations in magma flux could change $Q_{\text {ratio }}$ below and above the critical value to cause discrete jumps. Also, fracturing of the lithosphere due to propagating dikes will mechanically weaken the plate and could affect the initiation of ridge jumps.

\subsection{Relocation of the Mariana Back-arc Spreading Center}

Although we have focused on jumps of mid-ocean ridges to the location of nearby hotspots, the Mariana back-arc also experienced a jump in the location of seafloor spreading. Subduction of the Pacific plate beneath the Philippine Sea plate initiated at $\sim 50$ Ma with arc volcanoes first forming at $\sim 40 \mathrm{Ma}$ [47-49]. After $\sim 10 \mathrm{Myr}$ of volcanism, an initial rift of the volcanic arc and formation of seafloor spreading occurred 
at $\sim 30 \mathrm{Ma}$ [47]. A reorganization of plate spreading in SE Asia approximately 15Ma [50], caused the cessation of seafloor spreading [51]. Continued volcanism at the arc, which remained near the subduction front, led to the creation of a rheological weak zone [52] and initiation of a new seafloor spreading center at $\sim 7 \mathrm{Ma}[53]$.

A ridge jump due to magmatic heating of near-ridge lithosphere associated with arc volcanism is consistent with the conditions of our model. The cessation of spreading at $\sim 15 \mathrm{Ma}$, suggests that $Q_{\text {ridge }}$ decreased to 0 , promoting the initiation of a new spreading ridge at the arc due to the corresponding increase in $Q_{\text {hotspot }} Q_{\text {ridge }}$ (i.e. $Q_{\text {ratio }}$ ). The increased value of $Q_{\text {hotspot }} Q_{\text {ridge }}$, compounded by the cooling of the old ridge, may have decreased the necessary magma flux at the back arc required to relocate rifting (Figure 10). Thus, a smaller back-arc magma flux than required during active seafloor spreading

may initiate a new rift due to magmatism. In fact, magmatic heating may have promoted the initial arc rifting itself. There is evidence that relocation of back-arc spreading may also be associated with arc magmatism at other subduction zones, such as in the Mediterranean [54].

\subsection{Ridge Propagation on the Mid-Atlantic Ridge}

In the past $10 \mathrm{Myr}$, small-scale relocations of the Mid-Atlantic Ridge (MAR) have occurred through propagation of axis segments $[6,55,56]$. Many of the relocations are not considered to be affected by hotspot volcanism, but Sempéré et al. [6] find that, between $29^{\circ} \mathrm{N}$ and $31^{\circ} 30^{\prime} \mathrm{N}$, the segments with the largest propagation rates are associated with the largest volume of crust ( $\sim 9 \mathrm{~km}$ of crust at the segment center versus $\sim 7 \mathrm{~km}$ for the weaker segments). Ridge propagation has been widely understood in terms 
of fracture mechanics. The above correlation is consistent with the notion that thicker crust at segment centers elevates the pressure in the axial lithosphere and thus enhances the "driving pressure" (difference between pressure on a crack surface and in the far-field pressure) for ridge propagation [57]. We propose that enhanced magmatism could further increase the driving pressure of propagating ridge segments by reducing the tensile strength of the axial lithosphere.

Assuming that magmatic weakening of the plate is important to propagation of the above segments, we can use our scaling relationships to estimate the excess magma flux required to promote rift propagation of one segment over another segment (Figure 10). To initiate rifting $\mathrm{Q}_{\text {ratio }}$ must be greater than 1 and thus the required excess heating rate $\left(Q_{\text {hotspot }}-Q_{\text {ridge }}\right)$ is equal to $M Q_{\text {thin }}{ }^{a}$. We convert this excess heat estimate to a predicted excess magma flux using a latent heat of $500 \mathrm{~kJ} / \mathrm{kg}$ (see section 4.1). Our results predict that to initiate propagation the segment must have an excess magma flux between $\sim 4 \times 10^{-}$ ${ }^{7}$ and $\sim 1 \times 10^{-6} \mathrm{~m}^{2} \mathrm{~s}^{-1}\left(Q_{\text {hotspot }}-Q_{\text {ridge }}=0.8-4 \mathrm{~kJ} \mathrm{~m}^{-1} \mathrm{~s}^{-1}\right)$ for age offsets between 0.4 and 1 Myr. (Figure 10). For a half-spreading rate of $12 \mathrm{~km} / \mathrm{Myr}$, the above excess flux corresponds to an excess crustal thickness of 1000-2500 $\mathrm{m}$ at the propagating ridge relative to the dying segment. This range is consistent with the variations in crustal thickness estimated for the most rapidly propagating segments of the MAR between $29^{\circ} \mathrm{N}$ and $31^{\circ} 30^{\prime} \mathrm{N}[6,56]$. The obvious shortcoming of this study is the 2D geometry; $3 \mathrm{D}$ models are clearly necessary to more completely test the effects of magmatism on ridge propagation.

\section{CONCLUSIONS}


We have used 2D thermo-mechanical models to explore one of several possible factors that can promote jumps of mid-ocean ridge segments: heating of the lithosphere due to hotspot magmatism. We have quantified the effects of plate age, spreading rate, ridge migration rate, and the excess magmatic heating rate. Three fundamental parameters effectively describe the behavior of our model: 1) $Q_{\text {hotspot }}$, the initial integrated heating rate within the specified width of the heating zone; 2) $Q_{\text {ridge }}$, the initial integrated heating rate at the ridge axis; and 3) $Q_{\text {thin }}$, the instantaneous heating rate required to initiate a ridge jump. The key time scale is $t_{\text {cross }}$, which is the time needed to advect a piece of the lithosphere moving at the spreading rate through the zone of lithospheric thinning.

To initiate a ridge jump the function $Q_{\text {ratio }}=\left(Q_{\text {hotspot }} Q_{\text {ridge }}\right) / M Q_{\text {thin }}{ }^{a}$ with $a=2.68$ and $M=3.4 \times 10^{-3}$ must exceed 1 . For cases in which $Q_{\text {ratio }}>1$, the time required to initiate a ridge jump is on the order of $0.25-4$ Myr. When scaled by $t_{\text {cross }}$, the dimensionless time to a jump $\left(t_{\text {jump }} / t_{\text {cross }}\right)$ decreases nonlinearly with increasing $Q_{\text {ratio }}$. Increasing the excess hotspot heating rate $\left(Q_{\text {hotspot }} Q_{\text {ridge }}\right)$ increases $Q_{\text {ratio }}$ and decreases the time to a jump; increasing the spreading rate decreases $Q_{\text {ratio }}$ and thus increases the time to a jump. Additionally, the time required to initiate a ridge jump increases (or decreases) for a hotspot located on older (or younger) seafloor.

Hotspot migration toward a ridge axis is also found to produce ridge jumps for values of $Q_{\text {ratio }} \geq 1$. Once $Q_{\text {ratio }}$ exceeds 1, the age of lithosphere to which a jump occurs depends on the hotspot migration rate relative to the ridge, with faster migration rates jumping to younger seafloor. After a ridge jump, the ridge and hotspot are predicted to migrate together until the $Q_{\text {ratio }}$ (as defined relative to the initial jump location) falls 
below 1. At this point, the ridge and hotspot separate and no further ridge jumps are predicted. The location where the hotspot separates from the ridge axis also depends on the migration velocity, with faster migration rates separating earlier. We conclude that for ridges migrating away from a hotspot, steady hotspot magmatic heating alone will "capture" the ridge axis, but is unlikely to initiate repeated discrete ridge jumps. Other processes not considered here may be important to forming repeated discrete ridge jumps.

Application of our results to Iceland reveals that magmatic heating alone is capable of producing ridge jumps of the slow-spreading Mid-Atlantic Ridge in lithosphere younger than $\sim 1.5 \mathrm{Ma}$ for high-end magma flux estimates. In contrast, hotspots on older seafloor, or at faster spreading rates, including those with larger magma fluxes - like the Galápagos - are unlikely to initiate a ridge jump. This prediction is consistent with the lack of observed ridge jumps at the Galápagos over the last $\sim 5 \mathrm{Myr}$. Model results also provide a plausible mechanism for ridge jump formation in nonhotspot affected regions such as back-arc settings like the Marianas and ridge propagations along the Mid-Atlantic Ridge.

\section{ACKNOWLEDGMENTS}

The authors would like to thank an anonymous reviewer for comments that greatly strengthened our discussion of ridge jumps at Iceland. Additionally, the authors would like to thank R. Hey for discussions on the evolution of the Galápagos Spreading Center, and E. Chapp and F. Martinez for insights into the Mariana back-arc system. The map of Iceland was made using GMT version 3.4.2 by P. Wessel and W.F. Smith. 
Mittelstaedt, Ito and Behn were funded by NSF grant OCE03-51234 and OCE05-48672.

This is SOEST contribution XXXX. 


\section{References Cited}

[1] B. Parsons, J.G. Sclater, An analysis of the variation of ocean floor bathymetry and heat flow with age, J. Geophys. Res. 82 (1977) 803-827.

[2] R.N. Hey, Speculative propagating rift-subduction zone interactions with possible consequences for continental margin evolution, Geology 26 (3) (1998) 247-250.

[3] C. Nicholson, C.C. Sorlien, T. Atwater, J.C. Crowell, B.P. Luyendyk, Microplate capture, rotation of the western Transverse Ranges, and initiation of the San Andreas transform as a low-angle fault system, Geology 22 (1994) 491-495.

[4] R.G. Bohannon, T. Parsons, Tectonic implications of post-30 Ma Pacific and North American relative plate motions, Geol. Soc. Amer. Bull. 107 (8) (1995) 937-959.

[5] R.D. Muller, W.R. Roest, J. Royer, Asymmetric sea-floor spreading caused by ridge-plume interactions, Nature 396 (1998) 455-459.

[6] J.C. Sempéré, P. Blondel, A. Briais, T. Fujiwara, L. Geli, N. Isezaki, J.E. Pariso, L. Parson, P. Patriat, C. Rommevaux, The Mid-Atlantic Ridge between $29^{\circ} \mathrm{N}$ and $31^{\circ} 30 ' \mathrm{~N}$ in the last $10 \mathrm{Ma}$, Earth Planet. Sci Lett. 130 (1995) 45-55.

[7] M. Nakanishi, W.W. Sager, A. Klaus, Magnetic lineations within Shatsky Rise, northwest Pacific Ocean: Implications for hotspot-triple junction interaction and oceanic plateau formation, J. Geophys. Res. 104 (B4) (1999).

[8] B.S. Hardarson, J.G. Fitton, R.M. Ellam, M.S. Pringle, Rift relocation - a geochemical and geochronological investigation of a paleo-rift in northwest Iceland, Earth Planet. Sci Lett. 153 (1997) 181-196.

[9] C. Small, Observations of ridge-hotspot interactions in the Southern Ocean, J. Geophys. Res. 100 (1995) 17931-17946.

[10] R.D. Muller, J. Royer, L.A. Lawver, Revised plate motions relative to the hotspots from combined Atlantic and Indian Ocean hotspot tracks, Geology 21 (1993) 275-278.

[11] K.S. Krishna, D.G. Rao, Abandoned Paleocene spreading center in the northeastern Indian Ocean: evidence from magnetic and seismic reflection data, Marine Geology 162 (2000) 215-224.

[12] A. Briais, M. Rabinowicz, Temporal variations of the segmentation of slow to intermediate spreading mid-ocean ridges 1 . Synoptic observations based on satellite altimetry data, J. Geophys. Res. 107 (B5) (2002).

[13] J. Mammerickx, D. T. Sandwell, Rifting of old oceanic lithosphere, J. Geophys. Res. 91 (1986) 1975-1988.

[14] R.N. Hey, Tectonic evolution of the Coco-Nazca spreading center, Geol. Soc. Amer. Bull. 88 (1977) 1404-1420.

[15] J.M. Brozena, R. White, Ridge jumps and propagations in the South Atlantic Ocean, Nature 348 (1990).

[16] K.S. Krishna, D.G. Rao, M.V. Ramana, V. Subrahmanyam, K.V.L.N.S. Sarma, A.I. Pilipenko, V.S. Shcherbakov, I.V. Radhakrishna Murthy, Tectonic model for the evolution of oceanic crust in the northeastern Indian Ocean from the Late Cretaceous to the early Tertiary, J. Geophys. Res. 100 (B10) (1995) 20011-20024. 
[17] E. Mittelstaedt, G. Ito, Plume-ridge interaction, lithospheric stresses, and the origin of near-ridge volcanic lineaments, Geochem., Geophys., Geosys. 6 (6) (2005).

[18] D. Jurine, C. Jaupart, G. Brandeis, P.J. Tackley, Penetration of mantle plumes through depeleted lithosphere, J. Geophys. Res. 110 (B10104) (2005).

[19] J.M. Kendall, G.W. Stuart, C.J. Ebinger, I.D. Bastow, D. Keir, Magma-assisted rifting in Ethiopia, Nature 433 (2005).

[20] A. N. B. Poliakov, P.A. Cundall, Y.Y. Podladchikov, V.A. Lyakhovsky, An explicit inertial method for the simulation of viscoelastic flow: An evaluation of elastic effects on diapiric flow in two and three layers models, Flow and Creep in the Solar System: Observations, Modeling and Theory Kluwer Academic Publishers (1993) 175-195.

[21] P.A. Cundall, Adaptive density-scaling for time-explicit calculations, Int. Conf. Numerical Methods in Geomechanics 1 (1982) 23-26.

[22] L.L. Lavier, W.R. Buck, Half graben versus large-offset low-angle normal fault: Importance of keeping cool during normal faulting, J. Geophys. Res. 107 (B6) (2002).

[23] S.J. Mackwell, M.E. Zimmerman, D.L. Kohlstedt, High-temperature deformation of dry diabase with application to tectonics on Venus, J. Geophys. Res. 103 (B1) (1998) 975-984.

[24] C. Goetze, B. Evans, Stress and temperature in the bending lithosphere as constrained by experimental rock mechanics, Geophys. J. R. Astron. Soc. 59 (1979) 463-478.

[25] D.L. Turcotte, G. Schubert, Geodynamics, (2002) 456.

[26] P.D. Asimow, J. E. Dixon, C.H. Langmuir, A hydrous melting and fractionation model for mid-ocean ridge basalts: Application to the Mid-Atlantic Ridge near the Azores, Geochem. Geophys. Geosys. 5 (1) (2004).

[27] C. Wolfe, P.G. Okubo, G. Ekstrom, M. Nettles, P.M. Shearer, Characteristics of deep $(>13 \mathrm{~km})$ Hawaiian earthquakes and Hawaiian earthquakes west of $155.55^{\circ} \mathrm{W}$, Geochem. Geophys. Geosys. 5 (4) (2004).

[28] P.B. Kelemen, K. Koga, N. Shimizu, Geochemistry of gabbro sills in the crustmantle transition zone of the Oman ophiolite: implications for the origin of the oceanic lower crust, Earth Planet. Sci Lett. 146 (1997) 475-488.

[29] J. Maclennan, D. McKenzie, K. Gronvöld, L. Slater, Crustal accretion under northern Iceland, Earth Planet. Sci Lett. 191 (2001) 295-310.

[30] Y. Chen, W. Jason Morgan, A nonlinear rheology model for mid-ocean ridge axis topography, J. Geophys. Res. 95 (B11) (1990) 17,583-517,604.

[31] D.S. Wilson, R.N. Hey, History of rift propagation and magnetization intensity for the Cocos-Nazca spreading center, J. Geophys. Res. 100 (B6) (1995) 10,041010,056 .

[32] H. Jóhannesson, Jarðlagaskipan og próun rekbelta á Vesturlandi (Evolution of rift zones in western Iceland), Náttúrufræðingurinn 50 (1) (1980) 13-31.

[33] T.H. Torsvik, J. Mosar, E.A. Eide, Cretaceous-Tertiary geodynamics: A North Atlantic exercise, Geophys. J. Int. 146 (2001) 850-867.

[34] S.M. Jones, Test of a ridge-plume interaction model using oceanic crustal structure around Iceland, Earth Planet. Sci Lett. 208 (3-4) (2003) 205-218. 
[35] S. Garcia, N. Arnaud, J. Angelier, F. Bergerat, C. Homberg, Rift jump processes in Northern Iceland since $10 \mathrm{Ma}$ from 40Ar/39Ar geochronology, Earth Planet. Sci Lett. 214 (2003) 529-544.

[36] R.M. Allen, G. Nolet, W. Jason Morgan, K. Vogfjord, M. Nettles, G. Ekstrom, B.H. Bergsson, P. Erlendsson, G.R. Foulger, S. Jakobsdottir, B.R. Julian, M. Pritchard, S. Ragnarsson, R. Stefansson, Plume-driven plumbing and crustal formation in Iceland, J. Geophys. Res. 107 (B8) (2002).

[37] J.P. Canales, J.J. Danobeitia, R.S. Detrick, Emilie E.E. Hooft, R. Bartolome, D.F. Naar, Variations in axial morphology along the Galapagos spreading center and the influence of the Galapagos hotspot, J. Geophys. Res. 102 (B12) (1997) 27,341-327,354.

[38] G. Ito, J. Lin, C.W. Gable, Interaction of mantle plumes and migrating mid-ocean ridges: Implications for the Galapagos plume-ridge system, J. Geophys. Res. 102 (B7) (1997) 15,403-415,417.

[39] P.S. Hall, C. Kincaid, Melting, dehydration and the dynamics of off-axis plumeridge interaction, Geochem. Geophys. Geosys. 4 (9) (2003).

[40] C. Kincaid, J-G. Schilling, C.W. Gable, The dynamics of off-axis plume-ridge interaction in the uppermost mantle, Earth Planet. Sci Lett. 137 (1996) 29-43.

[41] D. W. Sparks, E. M. Parmentier, Melt extraction from the mantle beneath spreading centers, Earth Planet. Sci Lett. 105 (1991) 368-377.

[42] P.S. Hall, C. Kincaid, Melting, dehydration, and the geochemistry of off-axis plume-ridge interaction, Geochem. Geophys. Geosys. 5 (12) (2004).

[43] N. Sleep, Ridge-crossing mantle plumes and gaps in tracks, Geochem., Geophys., Geosys. 3 (12) (2002).

[44] P.R. Vogt, Asthenosphere motion recorded by the ocean floor south of Iceland, Earth Planet. Sci Lett. 13 (1971) 153-160.

[45] G. Ito, Reykjanes 'V'-shaped ridges originating from a pulsing and dehydrating mantle plume, Nature 411 (2001) 681-684.

[46] S.M. Jones, N. White, J. Maclennan, V-shaped ridges around Iceland: Implications for spatial and temporal patterns of mantle convection, Geochem. Geophys. Geosys. 3 (10) (2002) 1059.

[47] D.M. Hussong, S. Uyeda, 54. Tectonic processes and the history of the Mariana Arc: A synthesis of the results of Deep Sea Drilling Project Leg 60, Init. Rep DSDP 60 (1981) 909-929.

[48] M.A. Cosca, R.J. Arculus, J.A. Pearce, J.G. Mirchell, 40Ar/30Ar and K-Ar age constraints for the inception and early evolution of the Izu-Bonin-Mariana arc system, The Island Arc 7 (1998) 379-395.

[49] B. Taylor, Rifting and the volcanic-tectonic evolution of the Izu-Bonin-Mariana arc, Proc. Ocean Drilling Program, Sci. Res. ODP 126 (1992) 627-651.

[50] J.C. Sibuet, S.K. Hsu, X. Le Pichon, J.P. Le Formal, T.B. Reed, G. Moore, C.S. Liu, East Asia plate tectonics since 15Ma: constraints from the Taiwan Region, Tectonophysics 344 (2002) 103-134.

[51] A. Briais, P. Patriat, P. Tapponnier, Updated interpretation of magnetic anomalies and seafloor spreading stages in the South China sea: implications for the Tertiary tectonics of Southeast Asia, J. Geophys. Res. 98 (1993) 6299-6328. 
[52] M.S. Steckler, U. tenBrink, Lithospheric strength variations as a control on new plate boundaries: Examples from the northern Red Sea region, Earth Planet. Sci Lett. 79 (1986) 120-132.

[53] M. Sdrolias, W.R. Roest, R.D. Muller, An expression of Philippine Sea plate rotation: the Parece Vela and Shikoku Basins, Tectonophysics 394 (2004) 69-86.

[54] C. Faccenna, F. Funiciello, D. Giardini, P. Lucente, Episodic back-arc extension during restricted mantle convection in the Central Mediterranean, Earth Planet. Sci Lett. 187 (2001) 105-116.

[55] R.C. Searle, P.A. Cowie, N.C. Mitchell, S. Allerton, C.J. MacLeod, J. Escartin, S.M. Russell, P.A. Slootweg, T. Tanaka, Fault structure and detailed evolution of a slow spreading ridge segment: the Mid-Atlantic Ridge at $29^{\circ} \mathrm{N}$, Earth Planet. Sci Lett. 154 (1998) 167-183.

[56] J.E. Pariso, J.C. Sempere, C. Rommevaux, Temporal and spatial variations in crustal accretion along the Mid-Atlantic Ridge $\left(29^{\circ}-31^{\circ} 30^{\prime} \mathrm{N}\right)$ over the last 10 m.y.: Implications from a three-dimensional gravity study, J. Geophys. Res. 100 (B9) (1995) 17,781-717,794.

[57] J. Phipps Morgan, E. M. Parmentier, Causes and rate-limiting mechanisms of ridge propagation: a fracture mechanics model, J. Geophys. Res. (B10) (1985) 8603-8612.

[58] W. H. F. Smith, D. T. Sandwell, Bathymetric prediction from dense satellite altimetry and sparse shipboard bathymetry, J. Geophys. Res. 99 (1994) 21,803821,824 .

[59] P.C. LaFemina, T.H. Dixon, R. Malservisi, T. Arnadottir, E. Sturkell, F. Sigmundsson, P. Einarsson, Geodetic GPS measurements in south Iceland: Strain accumulation and partitioning in a propagating ridge system, J. Geophys. Res. 110 (B11405) (2005).

[60] M.-H. Cormier, K.C. Macdonald, East Pacific Rise $18^{\circ}-19^{\circ}$ S: Asymmetric spreading and ridge reorientation by ultrafast migration of axial discontinuities, $\mathrm{J}$. Geophys. Res. 99 (B1) (1994) 543-564. 

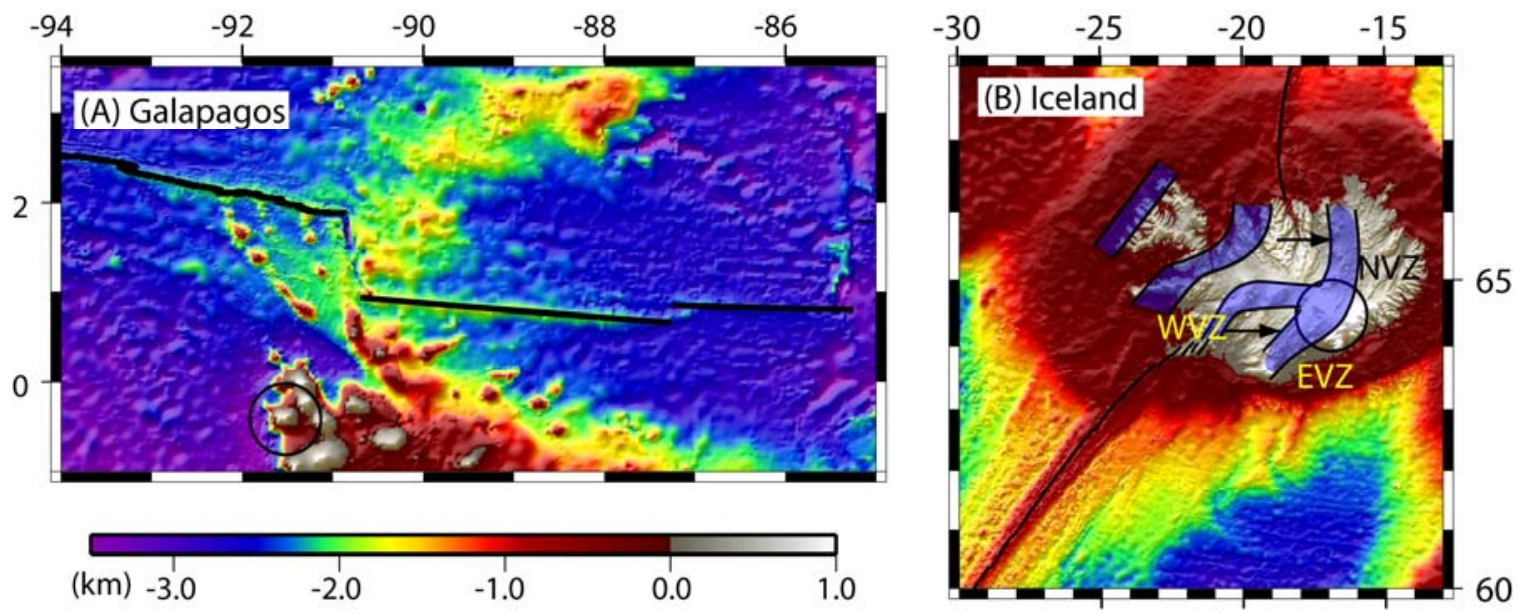

Figure 1. Satellite derived bathymetry [58] and digital elevation of the (A) Galápagos and (B) Iceland hotspots and the nearby ridges (black lines). Former ridge jumps kept the axis of the Galápagos Spreading Center close to the hotspot, but ridge jumps ceased approximately $5 \mathrm{Ma}$. At Iceland the Northern Volcanic Zone (NVZ) formed after completion of a ridge jump at $\sim 3 \mathrm{Ma}[8]$ and the Eastern Volcanic Zone (EVZ) has since propagated to the southwest. The Western Volcanic Zone (WVZ) appears to be dying due to the propagation of the EVZ [59]. The arrows indicate the direction of the most recent ridge jump towards the current location of the hotspot (black circle). The bands marking the previous ridge axes locations encompass previous estimates [8,35]. 


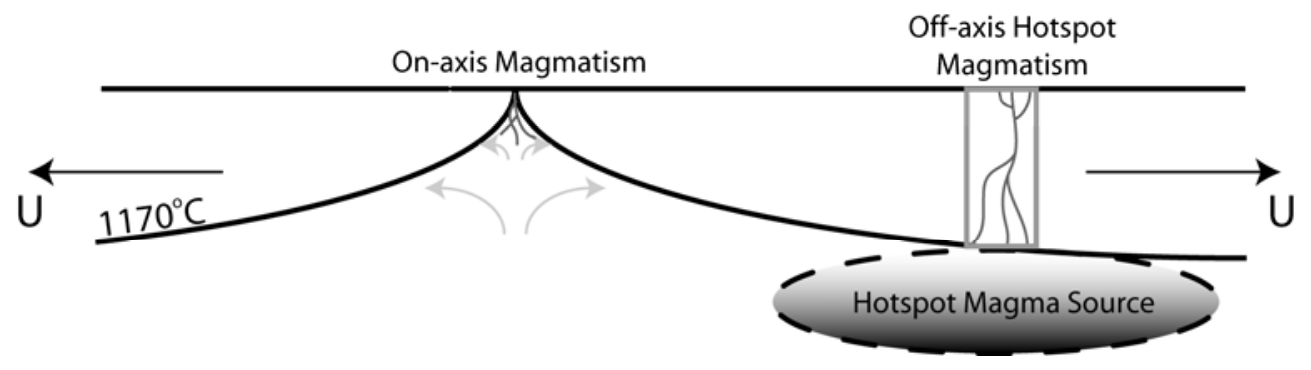

Figure 2. Conceptual model of magmatic heating of the lithosphere. A source of melt beneath the hotspot (dashed circle) provides magma which passes through the lithosphere in a magma transport zone (grey box) and proceeds to thermally weaken the lithosphere. The rate of heating is influenced by magma flux, spreading rate ( $U$, black arrows) and surface heat flow. Magmatism also heats and thermally weakens the ridge axis. 

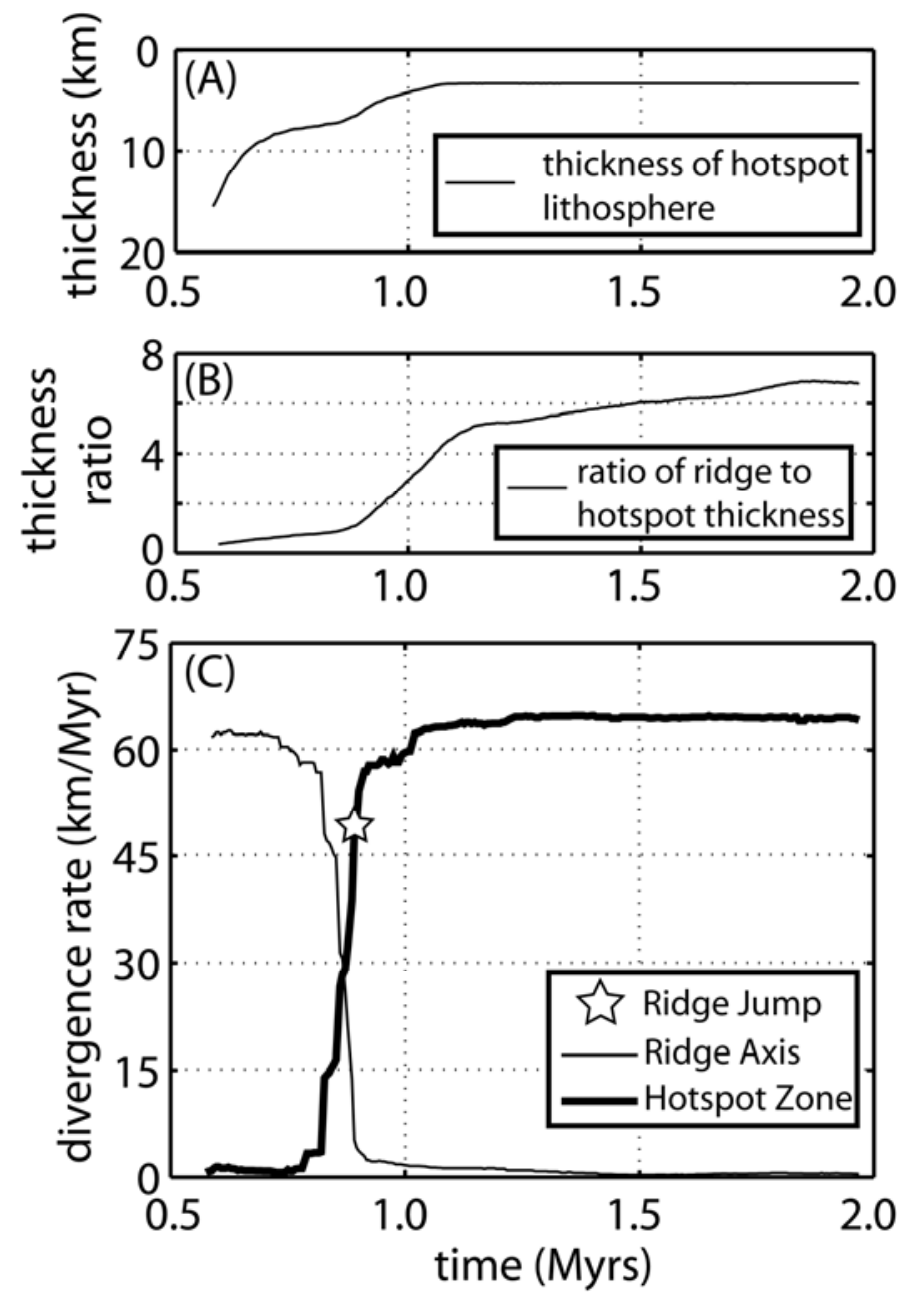

Figure 3. (A) Beneath the hotspot, the thickness of the lithospheric thermal boundary layer, defined by the $1170^{\circ} \mathrm{C}$ isotherm, changes dramatically during the formation of a new ridge axis. (B) The ratio of ridge axis thickness to off-axis lithosphere thickness passes 1 near the time of jump initiation. (C) A ridge jump (star) is defined as complete when the divergence rate off-axis (thick line) is equal to $80 \%$ of the original full spreading rate. The case shown here is for a half spreading rate of $30 \mathrm{~km} / \mathrm{Myr}$ and a $Q_{\text {hotspot }} Q_{\text {ridge }}$ of $161 \mathrm{~kJ} \mathrm{~m}^{-1} \mathrm{~s}^{-1}$ (see section 3.2 for a description of $Q_{\text {hotspot }}$ and $Q_{\text {ridge }}$ ). 


\section{Fixed Hotspot}
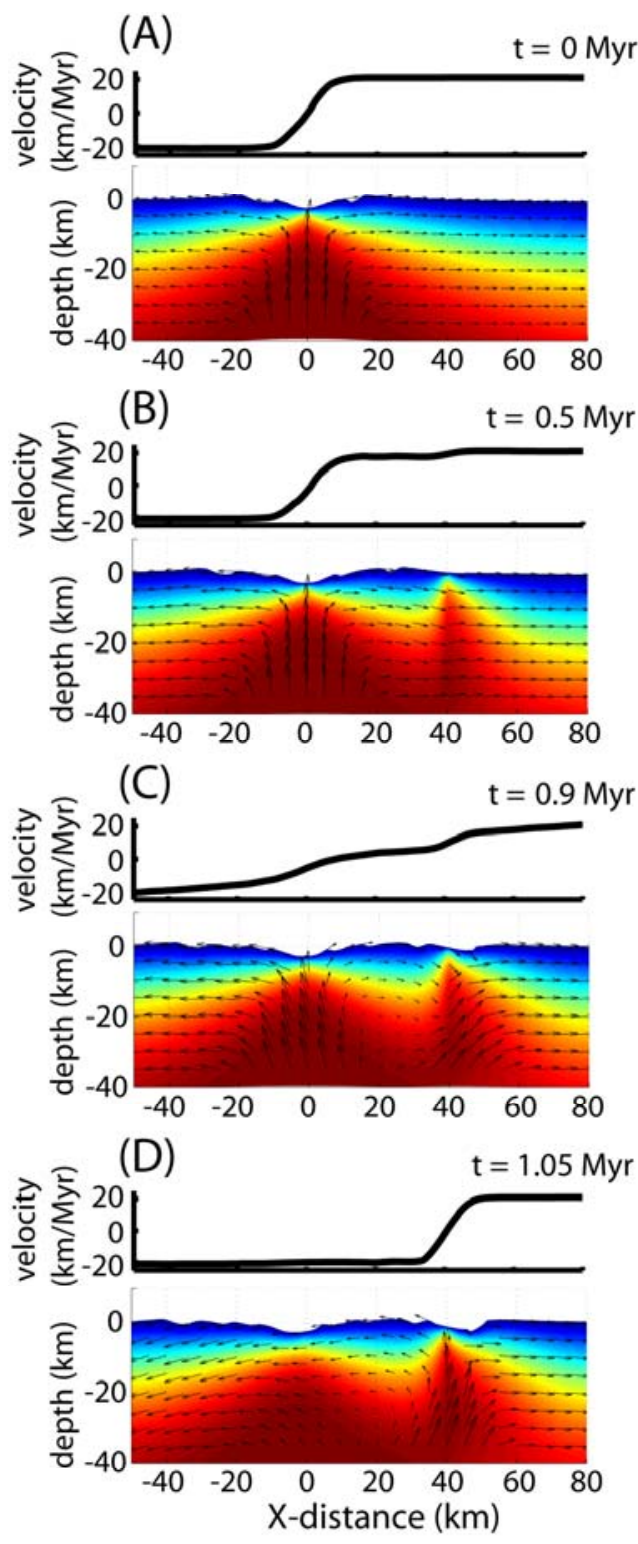

Migrating Hotspot

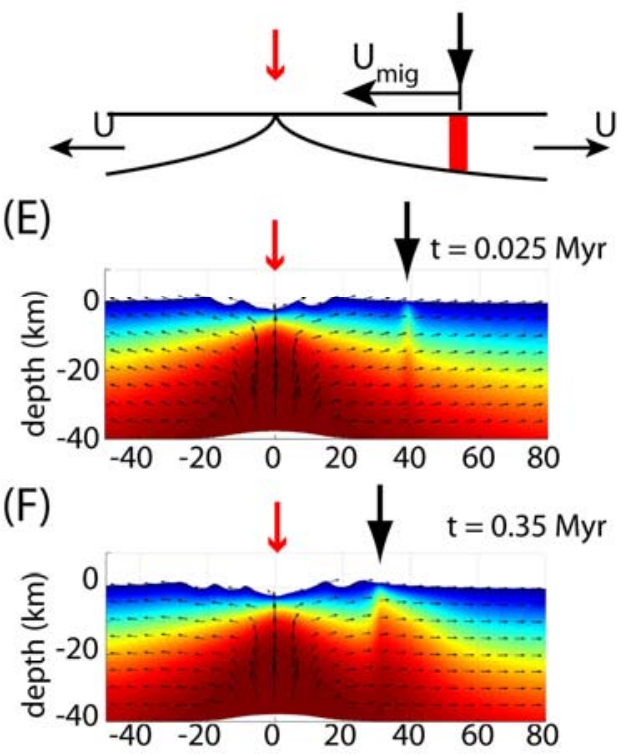

(G)
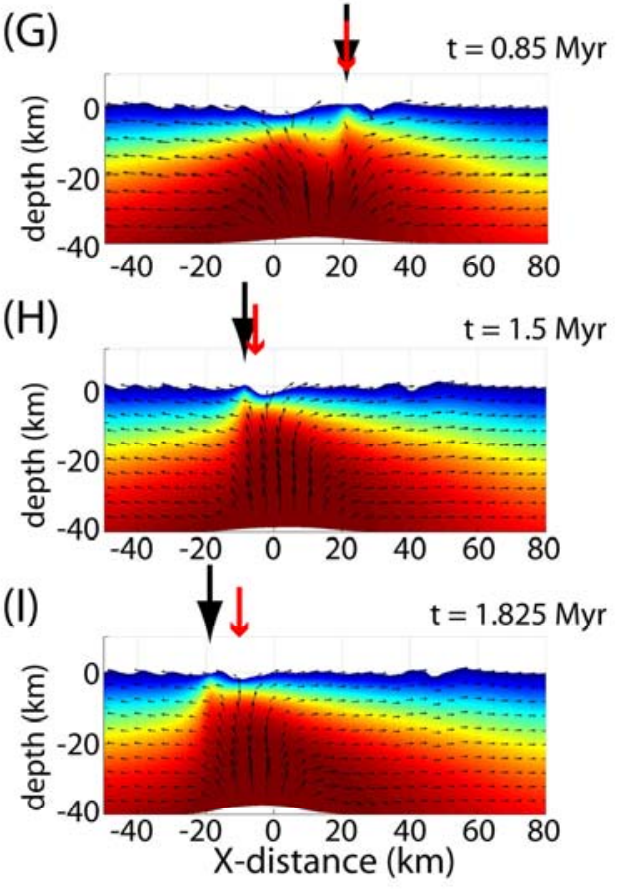

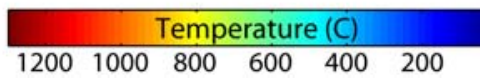

Figure 4. Thermal evolution of a ridge jump for a typical case of Type 1 (Type 2 is very similar) involving a hotspot that is fixed with respect to the ridge (left column, $Q_{\text {hotspot }}{ }^{-}$ $Q_{\text {ridge }}=83 \mathrm{~kJ} \mathrm{~m}^{-1} \mathrm{~s}^{-1}$ ) and Type 3 with a hotspot migrating relative to the ridge at a rate of $U_{m i g}=30 \mathrm{~km} / \mathrm{Myr}$ (right column, $Q_{\text {ratio }}$ varies with time as in figure 8 ). The half spreading rate is $U=20 \mathrm{~km} / \mathrm{Myr}$ for both cases. Colors panels show cross-sections of temperature and mantle flow (arrows); profiles above, show depth-averaged velocities within the upper $20 \mathrm{~km}$ of the model. (A) An initial square-root-of-age thermal profile is allowed to evolve to steady state and heat is subsequently added at an off-axis location. 
(B) Heating thins the lithosphere in and around the magma intrusion zone. (C) Beneath the hotspot, mantle upwelling is enhanced as seafloor rifting begins while spreading continues at the ridge axis. (D) Divergence shifts to the location of the hotspot and a new ridge axis is established. In the evolution of Type 3 cases, migration of the hotspot (large black arrow) relative to the ridge leads to ridge jumps and ridge-hotspot migration indicated by changes in the location of maximum divergence (small red arrow). (E) Initially the hotspot is located $40 \mathrm{~km}$ from the ridge and migrates toward the ridge axis. (F) Hotspot heating thins a broad area of lithosphere. (G) Lithospheric thinning leads to upwelling of hot mantle. (H) After a ridge jump, the hotspot and ridge migrate together. (I) The hotspot moves away from the ridge.

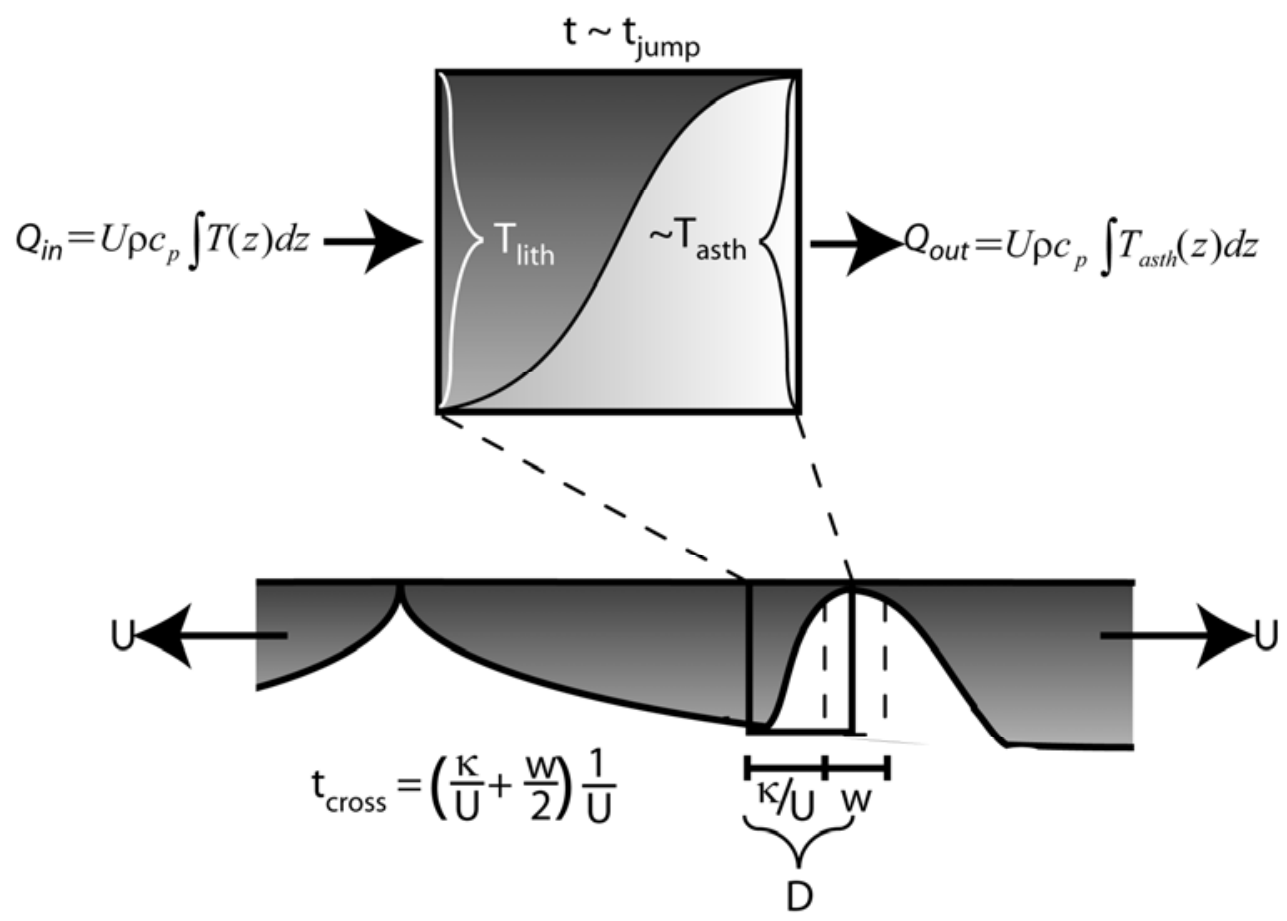

Figure 5. Cartoon of the thermal structure immediately prior to a ridge jump. The net advective heat flux passing out of the box, $Q_{t h i n}=Q_{o u t}-Q_{i n}$, is proportional to the depth integrated temperature multiplied by the spreading rate $(U)$. The width $(w)$ of the zone of magma penetration (dashed box) where heat is added is only a portion of the area over which heating of the lithosphere occurs $(D)$. The size of the zone outside of the magma penetration zone, $(D-w / 2)$, and the time needed to cross the total zone, $t_{\text {cross }}$, are described in section 3.2. 

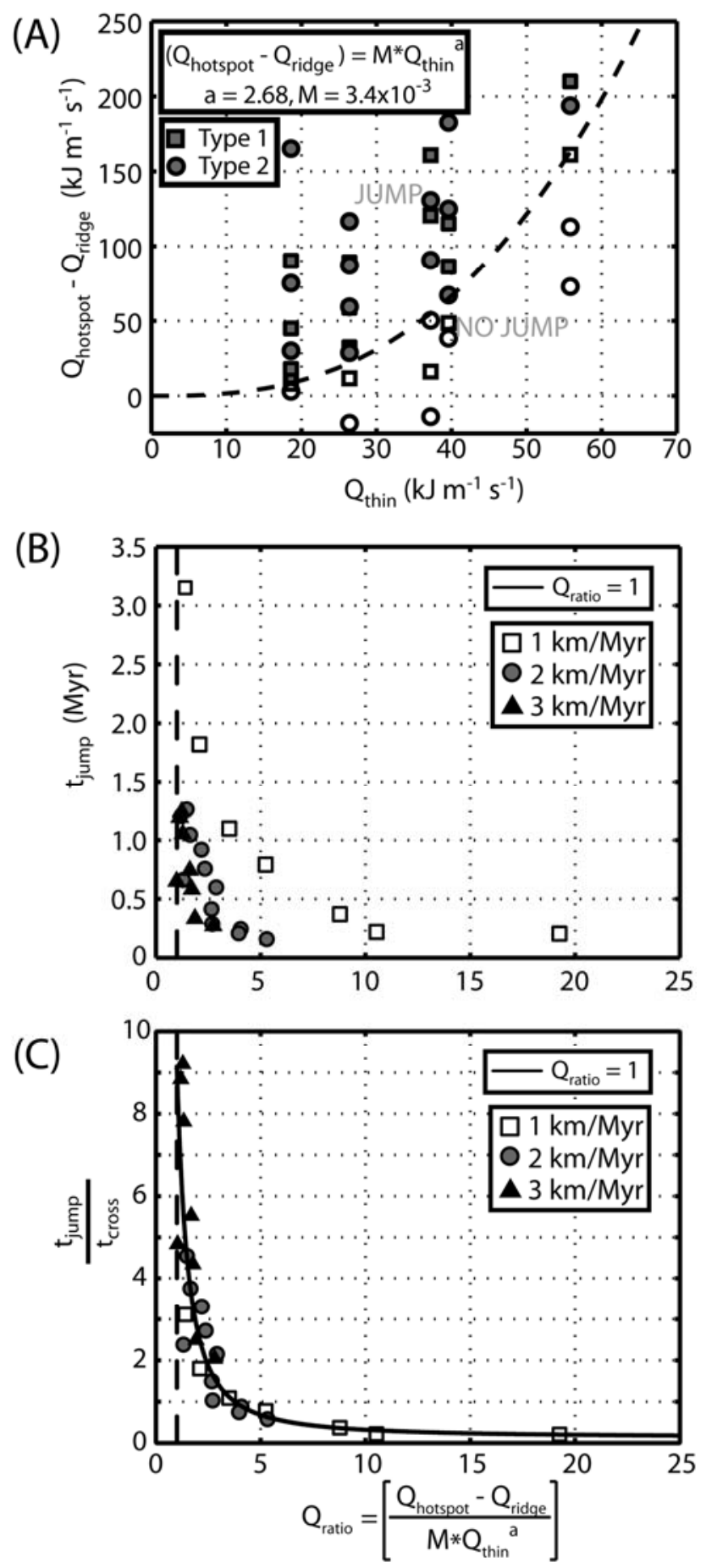

Figure 6. (A) Ridge jumps (solid symbols) occur when the value of the integrated heating rate at the hotspot $\left(Q_{\text {hotspot }}\right)$ minus the heat input at the ridge axis $\left(Q_{\text {ridge }}\right)$ is greater than $M Q_{\text {thin }}{ }^{a}$ where a $=2.68$ and $M=3.4 \times 10^{-3}$ (dashed line). Values of $Q_{\text {hotspot }} Q_{\text {ridge }}$ below this line do not result in ridge jumps (empty symbols). Results include cases where $Q_{\text {ridge }}=0$ (Type 1, squares) and cases with heating at the ridge axis (Type 2, circles). (B) The time to achieve a ridge jump $\left(t_{\text {jump }}\right)$ shows an asymptotic dependence upon $Q_{\text {ratio }}$. Different symbols mark ridge jump times for different $Q_{\text {ratios }}$ and spreading 
rates as labeled. (C) Normalizing by the timescale, $t_{\text {cross }}$, collapses all results onto a single curve which defines the scaling law, Eq. 11. Dashed line marks $Q_{\text {ratio }}=1$.

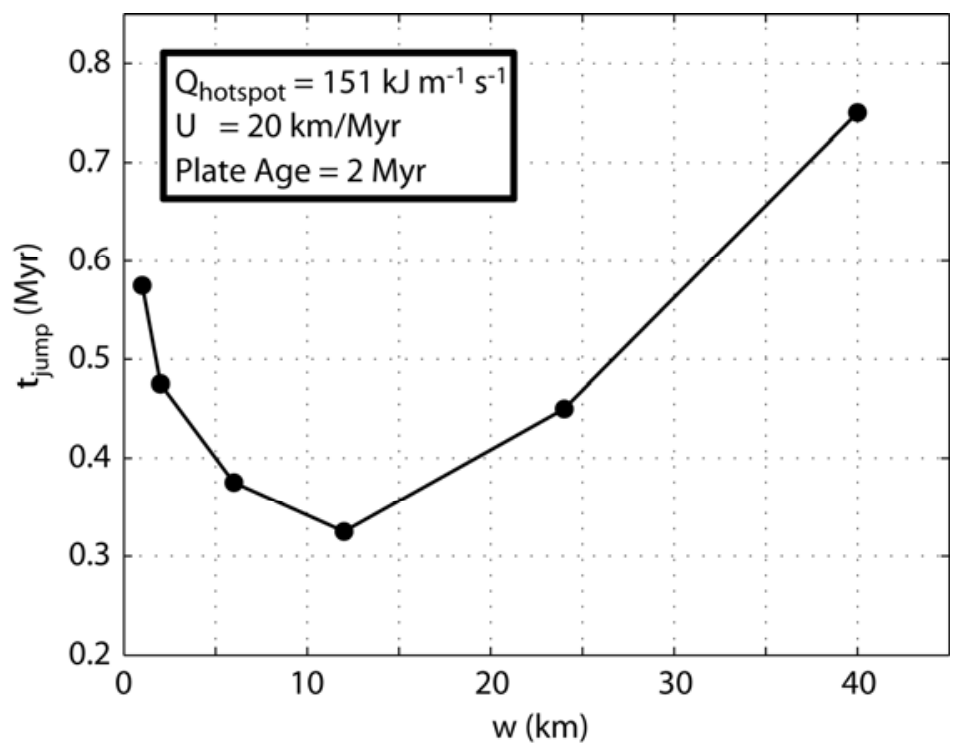

Figure 7. Models are run with a fixed $Q_{\text {hotspot, }}$ spreading rate $(20 \mathrm{~km} / \mathrm{Myr})$ and lithospheric age (2 Myr) at the center of the heating zone for off-axis heating zone widths, $w$, from 1 to $40 \mathrm{~km}$. 

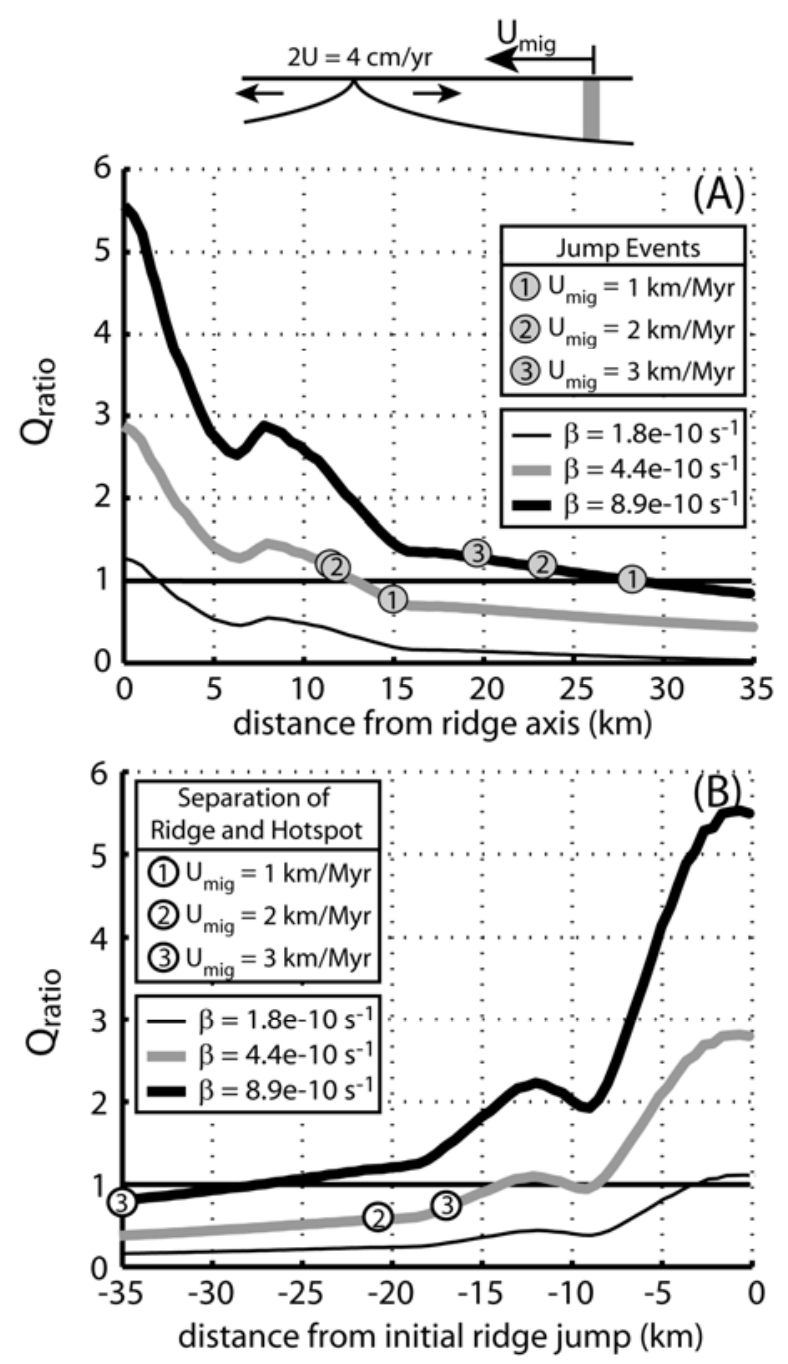

Figure 8. Predicted values of the $Q_{\text {ratio }}$ (solid curves) versus distance from the ridge axis at three different values of $\beta$ (Eq. 2). (A) When the hotspot migrates toward the ridge, a ridge jump is predicted to occur when $Q_{\text {ratio }} \geq \sim 1$. Ridge jumps (grey circles) occur closer to the ridge axis for larger migration rates, $U_{\text {mig. }}$ (B) After a ridge jump, the ridge and hotspot migrate together until $Q_{\text {ratio }}$ (see text) falls below 1 . When $U_{\text {mig }}<U$ they migrate together, but when $U_{\text {mig }} \geq U$ they separate at the shown locations (white circles). The local peak in the $Q_{\text {ratio }}$ at distances of 5-10 km from the ridge axis is associated with changes in the temperature profile due to faulting. 


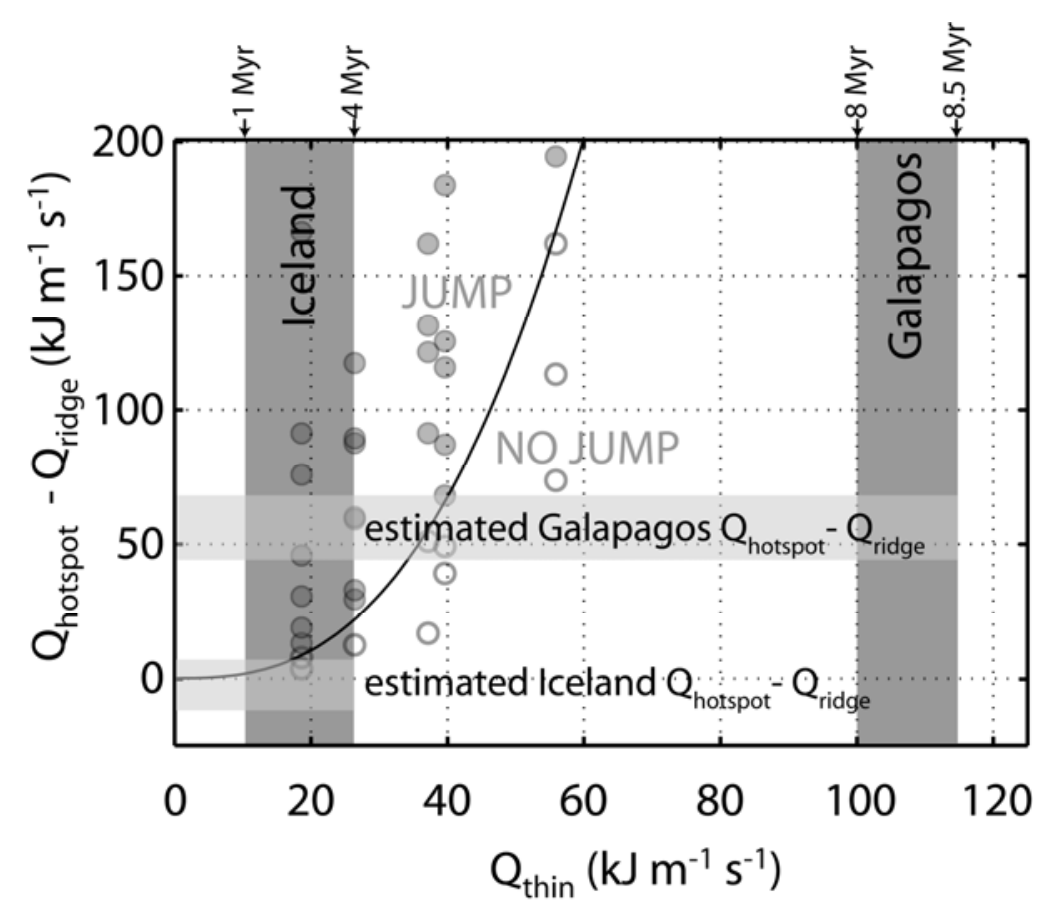

Figure 9. Estimates of $Q_{\text {hotspot }} Q_{\text {ridge }}$ (light grey bars) and $Q_{\text {thin }}$ (dark grey bars) for the Galápagos and Iceland hotspots compared to the theoretical limit of $Q_{\text {ratio }}$ (black curve, also Figure 6) suggest that the magma flux at Iceland could be sufficient to produce a ridge jump to $1.5 \mathrm{Myr}$. old seafloor at the slow spreading MAR (20 km/Myr full rate). Estimates were made on 1-4 Myr and 8-8.5 Myr old lithosphere for Iceland and the Galápagos respectively (top arrows). The estimated magma flux at the Galápagos, although larger, is clearly insufficient to initiate a ridge jump near the faster spreading Galápagos Spreading Center (60 km/Myr full rate) and to the older seafloor at the current location of the hotspot. See section 4.1 of the text for more details on estimates of $Q_{\text {hotspot}}, Q_{\text {ridge }}$ and $Q_{\text {thin }}$. The circular symbols show all model results in Figure 6. 


\section{(1) ridge propagations (2) ridge jumps (3) back-arc jumps}

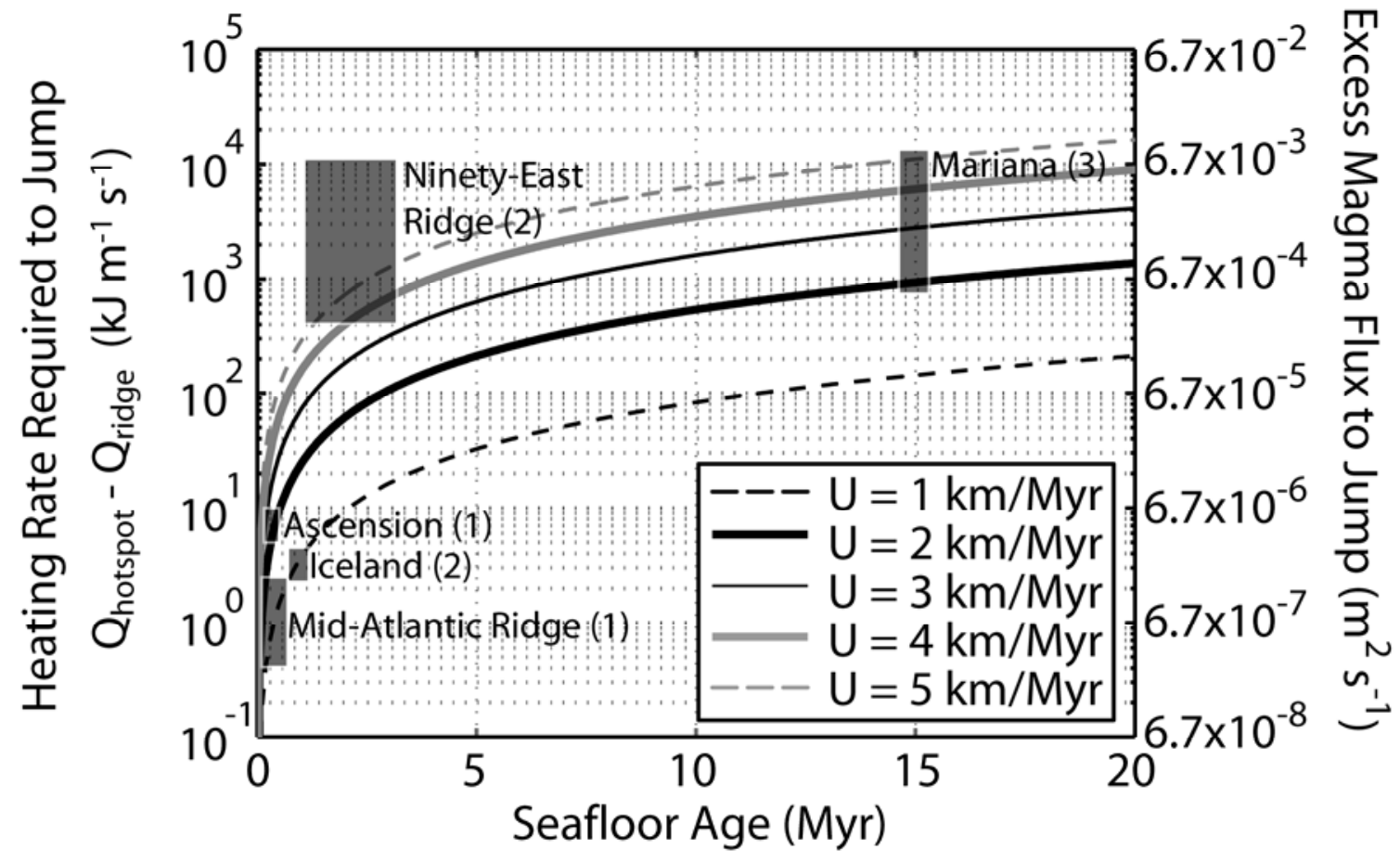

Figure 10. Curves show predictions of Eq. (11) for the excess magma fluxes and excess heating rates required to produce ridge jumps for an example range of spreading rates (1$50 \mathrm{~km} / \mathrm{Myr}$ ). Boxes show the required fluxes that are predicted for four settings based on estimates of spreading rates and seafloor age to which ridge relocations have been documented $[6,15,16,35,53,55,60]$. These example settings include ridge relocations in the form of (1) ridge propagations, (2) ridge jumps and (3) back-arc ridge jumps. 